\title{
EL NUEVO ESTATUTO DEL GOBIERNO EN LA CONSTITUCIÓN MARROQUÍ DE 2011
}

\author{
Amina El Messaoudi
}

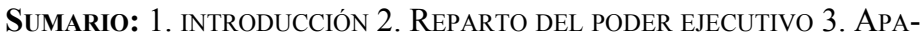
RICIÓN DE LA FIGURA DEL JEFE DE GOBIERNO 4. REGULACIÓN INSTITUCIONAL 5. BIBLIOGRAFÍA.

\section{INTRODUCCIÓN}

Situado en el centro de la organización política, el gobierno en sus diferentes funciones (o, según la expresión de Montesquieu, poseedor o no del «poder ejecutivo»), es una institución a través de la que se observa la evolución de los regímenes constitucionales. ¿Acaso no hablaba BLONDEL de «la universalidad del hecho gubernamental»? (BLONDEL, 1985: 355-384). La naturaleza del régimen constitucional cambiaría así en función de la formación y las atribuciones de la institución ejecutiva.

El análisis de la dualidad del poder ejecutivo en Marruecos, con arreglo a las tres primeras constituciones (1962, 1970 y 1972), permite apreciar un desequilibrio en las relaciones entre las dos instituciones de un Ejecutivo bicéfalo (EL MESSAOUd, A, 1998,583) Efectivamente, tanto el nombramiento del Gobierno como su disolución dependían únicamente de la voluntad del Rey (art. 24), y las competencias y las atribuciones de la institución gubernamental, pese a ser limitadas, dependían asimismo del ámbito de los poderes propios del jefe de Estado.

A partir de la cuarta Constitución (1992) y en respuesta a los memorandos de los partidos del bloque democrático, del 19 de junio y relativos a la refor- 
ma constitucional, la institución gubernamental quedó parcialmente rehabilitada, especialmente gracias a su investidura por parte de la Cámara de Representantes (art. 59) y a la mejora del estatuto del primer ministro, quien propone al monarca la lista de los ministros para su nombramiento (art. 24) y se encarga de la coordinación de las actividades ministeriales (art. 64). También bajo la responsabilidad del primer ministro, el Gobierno garantiza la ejecución de las leyes y organiza la Administración (art. 60).

Manteniendo el acervo del texto fundamental de 1992, la Constitución de 1996 amplía su alcance en un marco renovado (el bicameralismo), aunque preserva, con ciertos matices, el statu quo del Ejecutivo bicéfalo.

A pesar de los avances registrados en las constituciones de 1992 y 1996, las prerrogativas del Ejecutivo marroquí todavía suscitaban el debate sobre la reforma constitucional, sobre todo con el advenimiento del nuevo Reino, un debate centrado esencialmente en la redistribución de los poderes ejecutivos entre el Rey y el Gobierno y en el que se aludía a las amplias prerrogativas que el artículo 19 de las constituciones anteriores confería a la institución monárquica ${ }^{1}$. En otros términos, las atribuciones reales temporales y religiosas eran las que protagonizaban el debate sobre la reforma al comienzo del tercer milenio ${ }^{2}$. De esta manera, tras el acceso al trono del rey Mohammed VI, el debate sobre la reforma constitucional no descartaba la demanda de rehabilitación de la institución gubernamental, e insistía de manera específica en el refuerzo de las prerrogativas del primer ministro. Este afianzamiento fue uno de los siete fundamentos principales del discurso real del 9 de marzo de 2011 con vistas a una reforma constitucional. El cuarto fundamento de éste, está dedicado a consolidar el principio de separación y de equilibrio entre poderes. De entrada, recalca que el gobierno emana de la mayoría parlamentaria y a continuación señala «el fortalecimiento de la figura del primer ministro como jefe de un poder ejecutivo eficaz, plenamente responsable del Gobierno y la Administración Pública, y de la dirección y la aplicación del programa gubernamental» ${ }^{3}$.

En ese mismo sentido, la reconsideración y el refuerzo de las atribuciones del Ejecutivo marroquí han seguido siendo la piedra angular de los memorandos de los agentes políticos recibidos por la Comisión consultiva para la reforma de la Constitución, creada el 10 de marzo de $2011^{4}$. De igual modo,

${ }^{1}$ Sobre el artículo 19 de la antigua Constitución, véase MENNOUNI (1984).

2 Sobre las diferentes discusiones mantenidas acerca de la reforma constitucional en los partidos políticos del movimiento nacional, así como en el seno de determinadas asociaciones de la sociedad civil, véase El Messaoudi 2004: 9-26.

3 El discurso real del 9 de marzo de 2011 puede consultarse en www.maroc.ma.

4 Véanse los memorandos de los partidos políticos y los sindicatos recibidos por la Comisión consultiva para la reforma de la Constitución en: «La nueva Constitución del 
el discurso del Rey de 17 de junio de $2011^{5}$, que presenta el proyecto de Constitución con vistas al referéndum del 1 de julio de 2011, destaca que el Título V de la nueva carta magna debe ser «la emergencia democrática del poder ejecutivo bajo la dirección del jefe de Gobierno».

En consecuencia, la nueva Constitución del 29 de julio de $2011^{6}$ implica de manera evidente un traspaso de responsabilidades desde un Gobierno otrora casi exclusivamente en manos del Rey a un Gobierno de apariencia parlamentaria (D. MAUSs, 2011, 71).

Por tanto, para comprender el nuevo estatuto del Gobierno, es necesario interesarse por el texto constitucional en sí mismo, que de hecho solamente puede entenderse en relación con la cadena de textos que lo precedieron; y asimismo adoptar para su análisis un enfoque global del texto fundamental, vigente desde el 29 de julio de 2011.

La nueva arquitectura del Ejecutivo que revela la lectura de los Títulos III y V de la Constitución de 2011, relativos respectivamente a «la realeza» y al «poder ejecutivo», permite detectar una innovación particular que hace referencia al nuevo estatuto de la institución gubernamental, estatuto que experimenta una renovación por medio de tres factores esenciales: el reparto del poder ejecutivo (I), la aparición de la figura del jefe de Gobierno (II) y la reglamentación institucional (III).

\section{REPARTO DEL PODER EJECUTIVO}

De la lectura de los artículos 47, 89, 91, 92, 104 y 172 de la Constitución de 2011 se desprende una nueva dualidad del Ejecutivo marroquí. Si en las constituciones anteriores esta dualidad se caracterizaba por un desequilibrio neto en detrimento del primer ministro (El MessaOud, A.; 1996: 131), el reparto del poder ejecutivo entre el Rey y el jefe de Gobierno en la Constitución de 2011 anuncia un desdoblamiento equilibrado.

La primera traducción del reparto del Ejecutivo se manifiesta en el proceso de formación del Gobierno. En primer lugar, la Constitución de 2011 modifica fundamentalmente las normas relativas al nombramiento del jefe de Gobierno, que deja de ser discrecional. Según el artículo 47, el Rey nombra un jefe de Gobierno del partido político que se impone en las elecciones a la

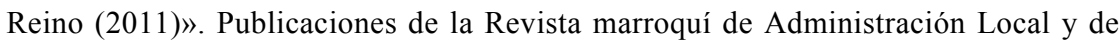
Desarrollo (REMALD). Colección «Textos y documentos», $n^{\circ} 246.2011$. pp. 37-388 (en árabe).

${ }^{5}$ El texto del discurso real del 17 de junio de 2011 puede consultarse en: www.maroc.ma.

${ }^{6}$ Dahir $n^{\circ} 1-11-91$ del 27 de chaabane 1432 (29 de julio de 2011) por el que se promulga el texto de la Constitución. B.O. n 5964 bis del 30 de julio de 2011 (pp. 19021928). 
Cámara de Representantes y teniendo en cuenta sus resultados. En adelante, el nombramiento del responsable del Gobierno depende de los resultados de las elecciones a la Cámara de Representantes, lo que supone una evolución profunda y considerable en el proceso de constitución del Gobierno. Recordemos, a este respecto, que el artículo 47 oficializa una práctica inaugurada por el rey Hassan II en 1998, cuando nombró primer ministro al primer secretario del Partido de la unión socialista de las fuerzas populares, formación que contó con respaldo del mayor número de votantes.

La segunda innovación del artículo 47 concierne a las modalidades de salida de los miembros del Gobierno, así como a la disolución del Ejecutivo en su totalidad. De esta manera, el jefe de Gobierno puede solicitar al Rey que ponga fin a las funciones de uno o de varios de los componentes (párrafo 4 del artículo 47), prerrogativa que por supuesto se añade a la facultad del jefe de Gobierno de proponer el nombramiento de los ministros, recogida por vez primera en el texto fundamental de 1992 (art. 24).

En este punto conviene realizar dos observaciones sobre los procedimientos previstos en el artículo 47 de la Constitución. La primera se refiere al párrafo 3 del mismo artículo, en virtud del cual el Rey puede tomar la iniciativa de cesar en sus funciones a uno o varios componentes del Gobierno, iniciativa que a partir de ahora, contrariamente al antiguo artículo 24, queda limitada por la necesidad de consultar al jefe de Gobierno, y que también requiere su ratificación, lo que implica una limitación ipso facto de la autonomía del monarca (MAUs, D.; 2012: 75).

La segunda observación se refiere al hecho de que la nueva Constitución no reproduce el antiguo artículo 60 (párrafo 1), según el cual «el Gobierno es responsable ante el Rey y ante el Parlamento», por lo que el Gobierno únicamente sería responsable ante la asamblea parlamentaria, tras el lógico nombramiento del jefe de Gobierno en vista de los resultados de las elecciones a la Cámara de Representantes. A esto se suma el cese de las funciones de los miembros del Gobierno, que se produce por vez primera tras la dimisión del jefe de Gobierno (art. 47, párrafo 6).

La formación del Gobierno, y en especial la elección de su jefe, depende por tanto, en primera y en última instancia, de la voluntad popular. El jefe de Gobierno debe proceder del partido vencedor de las elecciones a la Cámara de Representantes (art. 47) y la llegada al poder del Gobierno, queda sometida a la investidura de la primera Cámara del Parlamento, de conformidad con el artículo 88 de la Constitución.

Así pues, y contrariamente al texto constitucional anterior (artículos $60 \mathrm{y}$ 74) (El Messaoudi, A.; VinTRO, J.; 2005: 119), la investidura del Gobierno está sujeta a la confianza expresada por el voto de la mayoría absoluta de los miembros de la Cámara de Representantes a favor del programa gubernamental, lo que implica que la capacidad jurídica del Ejecutivo para gobernar 
proviene de esta investidura. En consecuencia, el mecanismo de llegada al poder del Gobierno marroquí se situaría en pie de igualdad con la creación de los gobiernos parlamentarios (MELLONI, 2012: 11).

Por otra parte, el reparto del poder ejecutivo se ilustra también con la creación del Consejo de Gobierno, que con anterioridad no gozaba de reconocimiento constitucional ${ }^{7}$. Este consejo, presidido por el jefe de Gobierno, delibera sobre una serie de competencias que no debe encubrir una retractación del ámbito de intervención del Consejo de Ministros presidido por el Rey (art. 49). De este modo, el Consejo de Ministros pierde, en beneficio del Consejo de Gobierno (art. 92), la facultad de examen de los decretos reglamentarios y de los decretos-ley, así como de todos los proyectos de ley, siendo esta última prerrogativa reemplazada por el derecho a deliberar solamente sobre los textos legislativos más importantes: leyes orgánicas, leyes marco, leyes de amnistía y orientaciones generales de la Ley de presupuestos (art. 49).

Esta reducción del ámbito de competencias del Consejo de Ministros va acompañada de un traspaso en beneficio del Consejo de Gobierno, toda vez que este último es el que delibera sobre «la política general del Estado» que anteriormente se deliberaba en el seno del Consejo de Ministros (art. 66 de la Constitución de 1996), órgano al que, de conformidad con la nueva carta magna, únicamente se insta a pronunciarse sobre «las orientaciones estratégicas de la política del Estado» (AzzouzI y CABANIS, 2011: 180).

Por otra parte, además de deliberar sobre la política general del Estado, el Consejo de Gobierno delibera igualmente sobre las políticas públicas, las políticas sectoriales, el compromiso de responsabilidad del Gobierno ante la Cámara de Representantes, las cuestiones de actualidad relacionadas con los Derechos Humanos y el orden público, los proyectos de ley, como el proyecto de Ley de presupuestos, los decretos-ley, los proyectos de decretos reglamentarios, los proyectos y decretos concernientes a los artículos 65 ( $2^{\circ}$ párrafo), 66 y 70 ( $3^{\text {er }}$ párrafo) de la Constitución actual, los tratados y los convenios internacionales antes de su presentación ante el Consejo de Ministros y la designación de los secretarios generales y los directores generales de las administraciones públicas, los presidentes de las universidades, los decanos y los directores de escuelas e institutos superiores (art. 92).

El ejemplo más evidente del reparto del poder ejecutivo entre el Rey y el jefe de Gobierno tiene lugar en el ámbito del nombramiento de altos cargos. En este caso, corresponde al Rey la designación de los puestos relacionados con funciones estratégicas y de seguridad, especialmente los walis y gober-

${ }^{7}$ Es importante recordar que, en los informes presentados ante la Comisión consultiva para la reforma de la Constitución, creada el 10 de marzo de 2011, la totalidad de los partidos políticos insistió en la constitucionalización del Consejo de Gobierno. 
nadores, los embajadores, los responsables de las administraciones encargadas de la seguridad interior, así como los responsables de las empresas públicas estratégicas que dependen del Consejo de Ministros (art. 49), mientras que al Consejo de Gobierno se le confía el nombramiento de los secretarios generales y los directores generales de las administraciones públicas, los presidentes de las universidades, los decanos y los directores de centros universitarios (art. 92). Los nombramientos que dependen del Rey en Consejo de Ministros se efectúan, además, a propuesta del jefe de Gobierno y por iniciativa del ministro correspondiente (art. 49).

Este nuevo reparto del ámbito de nombramientos merece ser destacado aquí por varios motivos, sobre todo porque anteriormente la designación de los altos cargos resultaba ajena al primer ministro y era competencia exclusiva del Rey, tanto en materia civil como militar (art. 30 de la Constitución de 1996). La constitución actual solamente reserva al Rey el nombramiento de los cargos militares en su condición de jefe supremo de las Fuerzas Armadas Reales. El monarca puede delegar este derecho (artículo 53).

\section{APARICIÓN DE LA FIGURA DEL JEFE DE GOBIERNO}

En el discurso real del 9 de marzo de 2011 que anunció una reforma constitucional basada en siete fundamentos principales, se subrayaba en el cuarto fundamento «el fortalecimiento de la figura del primer ministro como jefe de un poder ejecutivo eficaz, plenamente responsable del Gobierno y la Administración Pública, y de la dirección y la aplicación del programa gubernamental».

Conviene señalar, ante todo, que el cambio de denominación del responsable del Gobierno (de «primer ministro» a «jefe de Gobierno») tiene una importancia particular en el ejercicio el poder ejecutivo por parte de dicho responsable. Recordemos en este mismo sentido la diferencia entre el estatuto del «presidente del Consejo» en los cuatro primeros gobiernos de Marruecos (1955-1958) y el del «primer ministro», instaurado a partir de la primera Constitución (1962), un cambio de denominación que tendría un impacto en la naturaleza de las atribuciones del responsable del Gobierno (EL MESSAOUDI, 2001: 47).

Por otra parte, también es importante recordar que el término «jefe de Gobierno» aparece en 42 ocasiones en la nueva carta magna, lo que remite innegablemente al nuevo poder ejecutivo concedido al responsable de la institución gubernamental. En efecto, las prerrogativas de este último se extienden a lo largo del texto constitucional, especialmente en sus relaciones con el Rey y con el Parlamento.

En sus relaciones con el monarca, es preciso señalar la aparición del principio de delegación. El Rey puede delegar en el jefe de Gobierno la presiden- 
cia de un Consejo de Ministros con arreglo a un orden del día determinado (art. 48, párrafo 3), pudiendo ser solicitada la reunión de dicho órgano por el responsable de la institución gubernamental (art. 48, párrafo 2).

Igualmente, el Rey delega en el jefe de Gobierno la presidencia de una reunión del Consejo de Seguridad con arreglo a un orden del día determinado (art. 54, párrafo 2). El jefe de Gobierno forma parte de dicho consejo (art. 54, párrafo 3). En consecuencia y tras dicha delegación, el ámbito de la seguridad figura entre las áreas ejecutivas compartidas por el Rey y el jefe de Gobierno ${ }^{8}$.

Además, son numerosos los ámbitos compartidos por el Rey y el jefe de Gobierno, empezando por la ratificación de los dahirs reales por parte del jefe de Gobierno (art. 42) hasta la propuesta de este último de revisar la Constitución (artículos 172 y 173), derecho que no correspondía al primer ministro desde 1970, cuando el poder constituyente derivado residía únicamente en manos del Rey (art. 97 de la Constitución de 1970).

La aparición de la figura del jefe de Gobierno destaca asimismo en sus relaciones con el Parlamento. Así, y de conformidad con las disposiciones de los artículos 100 y 101 de la nueva Constitución, el jefe de Gobierno es llamado a responder mensualmente ante una o las dos cámaras del Parlamento sobre cuestiones de política general (art. 100, párrafo 3) según las modalidades previstas en el artículo 101, párrafo 1.

Por otra parte, el nuevo poder detentado por el jefe de Gobierno con respecto al Parlamento consiste especialmente en la potestad del aquel de disolver la Cámara de Representantes, poder que por supuesto no existía antes de la Constitución de 2011. Así pues, las disposiciones del artículo 104 tienen como objetivo reequilibrar los poderes entre el Legislativo y el Ejecutivo: «el jefe de Gobierno puede disolver la Cámara de Representantes, por decreto aprobado en Consejo de Ministros, previa consulta con el Rey, el presidente de esta Cámara y el presidente del Tribunal Constitucional. El jefe de Gobierno realizará ante la Cámara de Representantes una declaración centrada especialmente en las razones y los objetivos de esa decisión».

\section{REGULACIÓN INSTITUCIONAL}

Para el correcto funcionamiento de la nueva arquitectura del Ejecutivo marroquí y con el fin de poner de manifiesto el nuevo estatuto del Gobierno, el texto constituyente no olvida regular, más allá del estatuto, las condiciones de trabajo de las instituciones que ejercen el poder ejecutivo.

8 Ver para más detalles sobre las prerrogativas reales en la constitución 2011: EL Messaoudi, A., «De la Monarquía El Título III de la Constitución » In La Constitution marocaine. Commentaires, Editorial Sapere Aude, 2013, 95. 
De esta manera, las atribuciones del Rey en tanto que jefe del Estado se ejercen, de conformidad con el artículo 42, en virtud de los poderes que le han sido expresamente otorgados por la Constitución. A esta precisión, ausente en los textos constitucionales precedentes, se añade la supresión de cualquier referencia a la sacralidad del Rey que figuraba en las cartas magnas anteriores (art. 23), limitándose las disposiciones del nuevo artículo 46 a estipular que «la persona del Rey es inviolable y se le debe respeto»".

En cuanto al Gobierno, la reglamentación de su trabajo aparece por primera vez en la historia constitucional marroquí (EL MESSAOUDI, A; 2007, 11) con el nuevo artículo 87, que dispone que «una ley orgánica define, en particular, las normas relativas a la organización y a la dirección de las tareas del Gobierno y al estatuto de sus miembros. Asimismo, determina los casos de incompatibilidad con la función gubernamental, las normas relativas a la limitación de la acumulación de funciones, así como las que rigen el despacho de asuntos corrientes por parte del gobierno a cuyas funciones se haya puesto fin».

La nueva ley orgánica del Gobierno, en trámite de publicación en el momento de redactarse estas líneas, es una respuesta al silencio constitucional sobre cuestiones pertinentes, silencio que ha engendrado múltiples debates en la escena política y académica marroquí, a saber, las atribuciones del Gobierno para despachar los asuntos corrientes, el estatuto de las diferentes categorías ministeriales, las incompatibilidades totales de los miembros del Gobierno, etc. ${ }^{10}$.

La duración del gobierno que despacha los asuntos corrientes está precisada en el artículo 47 de la nueva Constitución, donde se recoge que el gobierno cuya dimisión haya sido aceptada seguirá despachando los asuntos corrientes hasta la formación de un nuevo Ejecutivo. Esta formalidad pretende evitar el vacío gubernamental y jurídico que ocasionaría un Gobierno saliente.

Una segunda ley orgánica prevista por el artículo 49 hace referencia al nombramiento de los cargos superiores en aplicación de las disposiciones de los artículos 49 y 92 de la Constitución. Dicha ley orgánica, publicada con el número 02-12, fija por vez primera en su artículo 4 los principios y criterios de nombramiento de los cargos superiores ${ }^{11}$. En consecuencia, y en aplica-

9 A título comparativo, el artículo 13 de la Constitución danesa establece que «el Rey tiene inmunidad; su personalidad es inviolable y sagrada»; por su parte, la Constitución belga del 17 de febrero de 1994 también observa, en su artículo 88, que la persona del Rey es inviolable.

10 Para ampliar esta información, véase El Messaoudi A. 2007: 6-20.

11 Véase el Dahir n ${ }^{\circ} 1-12-20$ del 27 de chaabane de 1433 (17 de julio de 2012) por el que se promulga la Ley Orgánica $n^{\circ}$ 02-12 relativa al nombramiento de los cargos supe- 
ción de las disposiciones del artículo 92 de la Constitución, se establecen tres grandes principios para el nombramiento de los altos cargos. Se trata de principios relativos a la igualdad de oportunidades, a la no discriminación y a la paridad entre mujeres y hombres.

En cuanto a los criterios de nombramiento, se trata ante todo de beneficiarse de sus derechos políticos y civiles; de disponer de un elevado nivel de educación y de la cualificación exigible; ser conocido por su integridad y su probidad y contar con experiencia profesional en las administraciones del Estado, en entes territoriales, en establecimientos o empresas públicos, o bien en el sector privado tanto dentro como fuera del país ${ }^{12}$.

Por otra parte, junto a las dos leyes orgánicas citadas anteriormente, la reglamentación de la institución gubernamental también se distingue por otras disposiciones constitucionales, que para algunos instauran la nueva jerarquía entre el jefe de Gobierno y los miembros de este. Jerarquía que se comprende, en primer lugar, a través de la facultad del primero de proponer la entrada y salida de cargos ministeriales (art. 47), a través de la petición que aquel realiza a estos para cumplir sus misiones (art. 93), pero sobre todo mediante el impacto que supone la dimisión del jefe de Gobierno, y que por vez primera conlleva el cese de las funciones del conjunto de su gabinete (art. 47, párrafo 6). Esta nueva jerarquía consagrada constitucionalmente permite la posibilidad de que el jefe de Gobierno ejerza un verdadero magisterio a través de su poder de decisión y de conciliación entre los componentes de su equipo gubernamental.

Siempre en términos de reglamentación del Gobierno, y comparando el nuevo texto constitucional con la antigua carta fundamental donde las prerrogativas de los ministros figuraban simplemente como atribuciones condicionales, a saber, la ratificación de los actos reglamentarios del primer ministro si ellos se encargaban de su ejecución (art. 63) y el ejercicio de determinados poderes del primer ministro si les eran delegados por este último (art. 64), la Constitución de 2011 procura dedicar a los ministros, además de los artículos anteriores, una nueva disposición que pone de manifiesto la responsabilidad de los titulares de carteras en el sector a su cargo y en la puesta en práctica de la política del Gobierno (art. 93). Por otra parte, este mismo artículo destaca el papel de los ministros en la realización de las misiones que les son confia-

riores en aplicación de las disposiciones de los artículos 49 y 92 de la Constitución en el Boletín Oficial no 6070 del 13 de ramadan de 1433 (2 de agosto de 2012), pp. 2487-2489.

12 Véase el Decreto $n^{\circ} 2-12-412$ del 24 de kaada de 1433 (11 de octubre de 2012) adoptado para la aplicación de los artículos 4 y 5 de la Ley Orgánica ${ }^{\circ}$ 02-12 relativa al procedimiento de nombramiento de los altos cargos cuya designación es objeto de deliberación en el Consejo de Gobierno, en el Boletín Oficial nº 6092 del 2 de hijja de 1433 (18 de octubre de 2012), pp. 2695-269. 
das por el jefe de Gobierno, siendo el Consejo de Gobierno la instancia a la que deben rendir cuentas.

En segundo lugar, la innovación del artículo 93 concierne a su párrafo 3, que presenta por vez primera la categoría de los «secretarios de Estado» como una categoría distinta de la de los otros miembros del Gobierno. Según el artículo 93, los ministros pueden efectivamente delegar una parte de sus atribuciones a los secretarios de Estado. Esta nueva jerarquía establecida constitucionalmente entre las dos categorías de los miembros del Gobierno (ministros y secretarios de Estado) también se desprende de la lectura del artículo 87 de la Constitución, que establece que «el Gobierno está compuesto por el jefe de Gobierno y los ministros, y asimismo puede incluir a los secretarios de Estado», mientras que según el antiguo artículo 59 la composición del Gobierno se limitaba a la categoría única de los «ministros», estando formado el Gobierno por el primer ministro y el resto de ministros (art. 59 de la Constitución de 1996).

Sin embargo, la principal innovación que afecta a la reglamentación del estatuto de los miembros del Gobierno consiste en la nueva incompatibilidad de la función ministerial con la de miembro del Parlamento, instaurada por el artículo 14 de la Ley Orgánica 27.11 relativa a la elección de los miembros de la Cámara de Representantes, que establece que «el mandato de un miembro de la Cámara de Representantes es incompatible con la condición de miembro del Gobierno ${ }^{13}$. Así, y tras la entrada en vigor de esta incompatibilidad, todos los miembros del Gobierno tendrán el mismo estatuto sin diferencia alguna, y los ministros «parlamentarios» privilegiados en relación con sus colegas, por la inmunidad prevista por la Constitución en su artículo 64, ya no tendrán cabida en la institución gubernamental.

Asimismo, y de manera más general, esta misma incompatibilidad acarreará la reserva del derecho de voto en el seno de la asamblea legislativa solamente a los parlamentarios. Esta nueva reglamentación del estatuto de los miembros del Gobierno se inscribe claramente en el principio de separación de poderes estipulado por el artículo primero de la Constitución.

Una última y novedosa reglamentación gubernamental consiste en el nuevo enjuiciamiento de la responsabilidad penal de los miembros del Gobierno, establecida por el nuevo artículo 94, según el cual la responsabilidad penal de los componentes del Ejecutivo no se juzgará, como indicaba el antiguo texto constitucional, ante el Tribunal Supremo (art. 89). La nueva Constitución dispone que «los miembros del Gobierno son penalmente responsables ante las jurisdicciones del Reino por los crímenes y delitos cometidos en el ejercicio de sus funciones» (art. 94).

13 Véase la Ley Orgánica ${ }^{\circ}$ 27-11 relativa a la Cámara de Representantes, en el Boletín Oficial n 5992 del 3 de noviembre de 2011, pp. 2346-2360. 
Para concluir, el nuevo estatuto del Gobierno no podría entenderse separadamente de la nueva arquitectura constitucional en la que por vez primera se precisan las nuevas funciones de los partidos políticos (art. 7) y de la oposición parlamentaria (art. 10), en la que asimismo se mencionan desde el preámbulo de la Constitución los principios de Estado de Derecho, de democracia participativa y de rendición de cuentas, y donde por primera vez se dedica un segundo título entero a las libertades y derechos fundamentales, compuesto por 22 artículos (19-40) y se añade un principio que tiene un efecto indudable en el estatuto del Gobierno, a saber, «la correlación entre la responsabilidad y la rendición de cuentas». En este mismo sentido, un término realiza una entrada espectacular en su estreno en el nuevo texto constitucional. Se trata en este caso del término «buena gobernanza», que aparece en doce ocasiones en la Constitución de 2011. El preámbulo lo menciona inicialmente como uno de los fundamentos de las instituciones de un Estado moderno, y el artículo 1 lo presenta como uno de los fundamentos del nuevo régimen constitucional ${ }^{14}$.

Finalmente, parece que del epígrafe «Poder ejecutivo» del Título V de la nueva Constitución marroquí se desprenden un refuerzo y una afirmación de poder gubernamental, especialmente en lo tocante a las atribuciones del jefe de Gobierno, que serán puestas de relieve por la ley orgánica prevista en el artículo 87. No obstante, son los partidos políticos quienes deben aceptar el desafío en relación con los modos de funcionamiento del nuevo estatuto de Gobierno que acaba de implantarse.

\section{BIBLIOGRAFÍA}

Azzouzi, A., CABANIS, A., Le néo-constitutionnalisme marocain à l'épreuve du printemps arabe, L'Harmattan, CMIESI, 2011.

Boutin, C., «La place du Souverain dans la nouvelle constitution du Royaume» In La constitution marocaine de 2011, Lectures croisées, REMALD Collection Thèmes actuels, 77, 2012, pp. 41-62.

El Messaoudi, A., « L'équilibre entre les pouvoirs dans les six constitutions marocaines » In cinquante ans de vie constitutionnelle au Maroc, Quel bilan ? Publications de l'Association Marocaine de droit Constitutionnel, El Maârif El Jadida, 2013, pp. 13-35.

${ }^{14}$ La noción de buena gobernanza se recoge en el duodécimo título de la Constitución, en primer lugar con los principios de buena gobernanza a los que el texto constituyente dedica siete artículos (156-160), seguidamente con las instancias encargadas de la protección y la promoción de los derechos humanos, de la buena gobernanza y del desarrollo humano y sostenible, y de la democracia participativa (161-171). 
El Messaoudi, A., «Réflexions sur l'équilibre institutionnel dans la nouvelle constitution marocaine», Annuaire de l'Afrique du Nord, CNRS, Paris, 1996, Tome XXXV, pp. 583-591.

El Messaoudi, A., «La dualité de l'exécutif au Maroc, Lecture constitutionnelle» In Etudes de Droit Constitutionnel, Association Tunisienne de Droit Constitutionnel, Centre d'Etudes et de Recherches Economiques et sociales, Tunis, (1999), pp. 131-143.

El Messaoudi, A., Les ministres dans le système politique marocain, Najah El Jadida, Casablanca, Maroc, 2001 (en arabe).

El Messaoudi, A., Alternance et réformes constitutionnelles In Omar Bendourou, Abdelmoughit Tredano et Mohamed Hamoudi, Alternance et Transition démocratique, Collection Droit Public collaboration de Konrad Adenauer, 2001 pp. 129-139.

EL Messaoudi, A., «les limites du travail gouvernemental» In Démocratie et transformations sociales au Maroc, Publications Faculté des lettres et des sciences humaines, Rabat, Série conférences et séminaires, N. 86, 2001, pp. 125-135 (en arabe).

El Messaoud, A., «Réforme constitutionnelle. Vrai faux débat ? Cahiers Bleus», Fondation Abderrahim Bouabid-Fondation Frederich Ebert, 2004, n 1, septembre, pp. 9-22.

El Messaoudi, A., y Vintró, J., «El proceso de formación del gobierno: prerrogativas reales y régimen parlamentario (1962-2002)», en El Messaoudi, A., y VINTRÓ, J. (coord.), Elecciones, partidos políticos y gobierno en Marruecos, Ed; Tirant Lo Blanch, (2005), pp. 119-145.

El Messaoudi, A., «Régulation juridique du gouvernement et transition démocratique au Maroc», Prologues, N. 37, 2007, hiver, pp. 6-20.

El Messaoudi, A., «L'équilibre entre les pouvoirs dans les six constitutions marocaines (1962-2011)» In Cinquante ans de vie constitutionnelle au Maroc. Quel bilan? Publications de l'Association marocaine de droit constitutionnel, El Maârif Al Jadida, 2013, pp: 13-34 (en arabe).

MAus, D., «L'exécutif dans la constitution marocaine de 2011» In la constitution marocaine de 2011. Analyses et commentaires Dir. Centre d'Etudes Internationales, LGDJ, 2012, pp. 71-84.

El Messaoudi, A., «De la Royauté» In Terol Becerra, J. M., La Constitution marocaine. Commentaires, Editorial Sapere Aude, 2013, pp. 95-107.

Rouvillois, F., «Réflexions sur la Monarchie démocratique à la marocaine» In La constitution marocaine de 2011. Lectures croisées. REMALD Collection Thèmes actuels, 77, 2012, pp. 63-79.

Rousset, M., «L'interprétation des pouvoirs du Roi dans la nouvelle constitution» In La constitution marocaine de 2011. Analyses et commentaires, Dir.Centre d'Etudes internationales. Librairie générale de droit et de jurisprudence, Paris 2012, pp. 47-70.

SAAF, A., Une nouvelle constitution au Maroc : Sortie de monarchie exécutive, Article publié sur le site du Nouvel observateur du 06-07-2011.

Terol Becerra, J. M., La Constitution marocaine. Commentaires, Editorial Sapere Aude, 2013. 
TITTLE: The new statute of the government in the Moroccan Constitution of 2011 .

RESUMEN: Una de las novedades más destacadas de la nueva arquitectura político-constitucional en Marruecos conformemente a la constitución 2011, es el nuevo estatuto del gobierno. En el presente artículo se analiza la nueva regulación de la institución gubernamental en la Constitución de 2011, regulación que lleva a la constitucionalización de reglas parlamentarias, tanto en lo que concierne la formación del gobierno como en lo que se refiere a sus competencias y atribuciones.

El objetivo sería, primero, evaluar el alcance de la autonomía políticoconstitucional de este nuevo modelo del gobierno y mostrar luego, a través de la comparación con los textos constitucionales anteriores, su impacto sobre la democratización del régimen político marroquí.

PaLABRAS ClaVE: Marruecos, Nueva constitución, Gobierno, Jefe del Gobierno, Repartición, Poder ejecutivo, regulación institucional.

ABSTRACT: One of the innovations most distinguished from the new political-constitutional architecture in Morocco in accordance with the constitution 2011, is the new statute of the government. In the present article it is analyzed the new regulation of the governmental institution in the Constitution of 2011, regulation that takes the constitutionalization of parliamentary rules, so much in what the formation of the government concerns as regarding its competitions and attributions.

The aim would be, first, to evaluate the scope of the political-constitutional autonomy of this new model of the government and to show then, through the comparison with the previous constitutional texts, its impact on the democratization of the political Moroccan regime.

KEY WORDS: Morocco, New constitution, Government, Head of State, Distribution, executive Power, institutional regulation. 
